\title{
Tomato Phytonutrients Balance UV Response: Results from a Double-Blind, Randomized, Placebo-Controlled Study
}

\author{
Katharina Groten ${ }^{\mathrm{a}} \quad$ Alessandra Marini $^{\mathrm{a}}$ Susanne Grether-Beck ${ }^{\mathrm{a}}$ \\ Thomas Jaenicke $^{a}$ Sally H. Ibbotson ${ }^{b}$ Harry Moseley ${ }^{b}$ James Ferguson $^{b}$ \\ Jean Krutmann ${ }^{a, c}$ \\ ${ }^{a}$ IUF - Leibniz Research Institute for Environmental Medicine, Düsseldorf, Germany; ${ }^{b}$ Department of \\ Dermatology, Ninewells Hospital and Medical School, Dundee, UK; ${ }^{`}$ Medical Faculty, Heinrich Heine University, \\ Düsseldorf, Germany
}

\section{Keywords}

Carotenoids · Oral photoprotection · Erythema formation . UVB · Double-blind, randomized, placebo-controlled study

\begin{abstract}
Background: Our previous double-blinded, placebo-controlled cross-over study indicated that a nutritional supplement named lycopene-rich tomato nutrient complex (TNC) can protect from UVA1-induced $(340-400 \mathrm{~nm})$ and UVA(320-400 nm)/UVB-induced (280-320 nm) upregulation of molecular markers associated with oxidative stress, inflammation, and ageing. Objectives: in the current double-blind, randomized, placebo-controlled multicenter study, we analyze whether a similar, synergistic carotenoid-rich TNC can protect from broadband UVB-induced threshold erythema formation assessed as increase in minimal erythemal dose (MED) reading, the intensity of erythema formation, and the upregulation of molecular markers associated with inflammation and immunosuppression, and whether this correlates with carotenoid blood levels. Methods: One hundred and forty-nine healthy volunteers were randomized to two groups and subjected to a 5-week washout phase, followed
\end{abstract}

by a 12-week treatment phase receiving either $15 \mathrm{mg}$ lycopene, $5.8 \mathrm{mg}$ phytoene and phytofluene, $0.8 \mathrm{mg} \beta$-carotene, $5.6 \mathrm{mg}$ tocopherols from tomato extract, and $4 \mathrm{mg}$ carnosic acid from rosemary extract per day or placebo made from medium-chain triglycerides. At the end of each phase, MED determination, UVB irradiation, chromametry, biopsies, and blood samples were undertaken. Results: The active supplement was well tolerated. Interestingly, no significant difference was seen in the MED between the active-supplement and placebo groups, as determined by visual grading by expert assessors. Of note, the carotenoid-containing supplement significantly protected against UVB-induced erythema formation measured as $\Delta \mathrm{a}^{*}$ after the intervention minus $\Delta \mathrm{a}^{*}$ after the washout phase as compared to the placebo. Moreover, intake of the active supplement significantly protected against UVB-induced upregulation of IL6 and TNFa as compared with the intake of placebo. Lastly, carotenoid plasma levels were significantly increased. Conclusion: This well-tolerated carotenoid-containing supplement significantly protected against UVB-induced erythema formation and upregulation of proinflammatory cytokines in healthy volunteers.

(c) 2019 The Author(s)

Published by S. Karger AG, Basel

\begin{tabular}{ll}
\hline KARGER & $\begin{array}{l}\text { () } 2019 \text { The Author(s) } \\
\text { Published by S. Karger AG, Basel Oper }\end{array}$ \\
E-Mail karger@karger.com & $\begin{array}{l}\text { This article is licensed under the Creative Commons Attribution- } \\
\text { wonCommercial-NoDerivatives 4.0 International License (CC BY- }\end{array}$ \\
www.karger.com/spp & $\begin{array}{l}\text { NC-ND) (http://www.karger.com/Services/OpenAccessLicense). } \\
\text { Usage and distribution for commercial purposes as well as any dis- } \\
\text { tribution of modified material requires written permission. }\end{array}$
\end{tabular}

Prof. Dr. Jean Krutmann

IUF - Leibniz Research Institute for Environmental Medicine

Auf m Hennekamp 50

DE-40225 Duesseldorf (Germany)

E-Mail Jean.Krutmann@IUF-Duesseldorf.de 


\section{Introduction}

The concept of oral photoprotection by antioxidant micronutrients gained very popular over the last decades $[1,2]$. In case of topical sunscreens, the sun protection factor is a simple and noninvasive tool to quantify the photoprotective activity. The latter is defined as a quotient of the minimal erythemal dose (MED) under treatment divided by the MED without intervention representing a measure for acute deleterious effects of UV irradiation [3]. An increased MED after intervention with a nutritional supplement can also therefore be used as an indicator of photoprotection in studies of potential orally ingested photoprotectants. A special focus was on $\beta$-carotene, which had been shown in a meta-analysis to provide significant protection against UV-induced erythema if taken at least over a period of 10 weeks [4]. Safety concerns after long-term intake of $\beta$-carotene at nonphysiological levels arose when adverse effects on the incidence of lung cancer in smokers and workers exposed to asbestos were found [5]. To circumvent this issue, other carotenoids such as lycopene or lutein came into focus. Recently, a double-blinded, placebo-controlled crossover study has shown that both these ingredients provided significant protection against UVA- or UVA/UVB-induced upregulation of UV-inducible markers such as heme oxygenase 1 , intercellular adhesion molecule 1 , and matrix-metalloproteinase 1 [6]. Some limitations of that study were (i) the relatively low number of volunteers included and (ii) the lack of showing an effect on the physiological erythemal skin response after intervention with the active supplement. In order to complement and strengthen the results of that study, we therefore performed a double-blind, randomized, placebo-controlled, multicenter follow-up study to assess as primary objective the effect of carotenoid-rich tomato nutrient complex (TNC; containing and rosemary extract) on the acute UV radiation-mediated erythemal skin response; i.e., (i) MED and (ii) intensity of erythema, compared with the placebo cohort following 12 weeks of twice daily oral supplement. As secondary objective, we wanted to evaluate the effect of carotenoid-rich TNC compared to that of placebo after 12 weeks of b.i.d. (twice a day) supplementation on skin biopsy biomarkers indicative for immunosuppression or inflammation. Analysis of UV-induced gene expression was very helpful to address photodamage to human skin in vivo in the previous study [6]. With regards to UVB, IL1 a was shown to be upregulated in keratinocytes in vitro and in vivo [7, 8]. IL10 was shown to be induced in keratinocytes in vitro and in human skin in vivo, where it exerts profound immunosuppressive activities [9]. Proinflammatory cytokines such as TNFa and IL6 are induced upon UVB treatment in keratinocytes and in humans on mRNA and protein level $[10,11]$. For a detailed review on UVB-induced cytokine production by keratinocytes or Langerhans cells, see [12].The listed proinflammatory cytokines act in a cascade fashion to induce inflammation with initial release by keratinocytes or inflammatory cells in the skin and subsequent synergizing with UV-irradiated keratinocytes to further increase their cytokine production finally affecting local and systemic immunosurveillance $[12,13]$.

\section{Materials and Methods}

\section{Materials}

Carotenoid-rich TNC soft gel capsules contained $7.5 \mathrm{mg}$ lycopene, $2.9 \mathrm{mg}$ phytoene and phytofluene, $0.4 \mathrm{mg} \beta$-carotene, $2.8 \mathrm{mg}$ tocopherols from tomato extract, and $2 \mathrm{mg}$ carnosic acid from rosemary extract per capsule ( 2 capsules per daily dose). The placebo was packaged in an identically looking soft gel capsule and consisted of medium-chain triglycerides. Both treatments were obtained from Lycored Ltd., Be'er Sheva, Israel.

\section{Study Design}

This study was approved by the local Ethics Committees of (i) the Heinrich Heine University, Düsseldorf, Germany (reference No. 4194), and (ii) the University of Dundee, Scotland, UK (No. SC015096). It was conducted at the IUF - Leibniz-Research Institute for Environmental Medicine, Düsseldorf, Germany, and at the Photobiology Unit, Department of Dermatology, Ninewells Hospital and Medical School, Dundee, UK, according to the ethical rules stated in the principles of the Declaration of Helsinki and the International Council for Harmonisation of Technical Requirements for Pharmaceuticals for Human Use. We conducted a randomized, double-blind, placebo-controlled, parallel-group, multicenter clinical trial in which each subject was randomized to receive carotenoid-rich TNC or placebo for a period of 12 weeks in a parallel-group design. A total of 149 subjects (female or male) were enrolled into the study, and 145 subjects completed the trial as planned. The treatment groups were stratified based on the age category, gender, and smoking to ensure equal distribution of such population within the two treatment arms (Table 1). The group taking the active supplement included 75 volunteers ( 56 female, 19 male), and the group taking placebo consisted of 74 volunteers (59 female, 15 male). The age distribution did not differ in both arms of the study (mean ages were 40.9 and 40.9 years). The age of the volunteers ranged from 20 to 50 years. Current smokers were very rare; in the carotenoid-rich TNC group, there were 5 smokers (7\%), and in the placebo group 3 (4\%). For ethical reasons, only two-thirds of the volunteers were asked for biopsies to be analyzed for expression of molecular markers. The subjects enrolled were distributed according to an online block randomization service by the sponsor; block size was 2 , allocation ratio 1:1. Volunteers and investigators were unaware of the treatment. 
Table 1. Baseline demographics and characteristics

\begin{tabular}{lcc}
\hline & Carotenoid-rich Placebo \\
& TNC \\
\hline Participants, $n$ & 75 & 74 \\
Females, $n$ (\%) & $56(75)$ & $59(80)$ \\
Males, $n$ (\%) & $19(25)$ & $15(20)$ \\
Mean age (SD), years & $40.9(10.3)$ & $40.9(10.1)$ \\
Mean BMI (SD) & $25.8(2.8)$ & $25.3(3.0)$ \\
Mean initial lycopene level, nM & 676 & 710 \\
Median initial lycopene level, nM & 646 & 670 \\
Mean initial phytofluene level, nM & 65 & 80 \\
Median initial phytofluene level, nM & 51 & 46 \\
Mean initial phytoene level, nM & 54 & 29 \\
Median initial phytoene level, nM & 50 & \\
\hline
\end{tabular}

All individuals were of good general health with a body mass index $\leq 30$. Their Fitzpatrick skin type was type I-II. With regards to eating habits, a normal diet and the willingness to follow a lycopene- and antioxidant-restricted diet was requested. Exclusion criteria were sunbed use and pregnancy. The study was conducted between January 2014 and September 2016.

\section{Determination}

The MED was determined with a dermalight ${ }^{\circledR} 80$ MED tester (Dr. Hönle, Gilching, Germany) in the broadband UVB range on visits 2 and 7 on both sides of the buttock by visual grading undertaken by expert assessors. The dermalight 80 MED tester serves for the definition of the MED according to the choice of the light source and skin type. The device contains a foil with 10 different test fields. The varying dosage in the test fields is caused by varying sizes of outlets and therefore varying UV irradiation.

\section{Chromametry}

MED was read $24 \mathrm{~h}$ after MED testing. Directly after the MED reading, a dose of $1.25 \mathrm{MED}$ was applied on an additional field $(12 \times 12 \mathrm{~mm})$ of the buttock for skin color determination by chromametry (Chromameter CR400; Konica Minolta Sensing Europe B.V., Bremen, Germany) and for taking biopsies with a dermalight $80 \mathrm{MED}$ tester (Dr. Hönle). The erythema formation was measured as change of skin color $\mathrm{a}^{*}$, which reflects the redness of the skin according to the Commission Internationale de l'Eclairage, as evaluated in [14]. We followed the recommended guidelines for skin color determination [15]. In this regard, color is expressed in a device-independent, three-dimensional color space reflected by the variables $\mathrm{L}^{*}, \mathrm{~b}^{*}$, and $\mathrm{a}^{*}$. The latter $\mathrm{a}^{*}$ values represent green in the negative direction and red in the positive direction. The dose of $1.25 \mathrm{MED}$ was selected according to prior experience [16].

\section{Assessment of Blood Samples}

Blood samples for carotenoid determination were collected after a 5-week washout phase, at randomization, after 4 weeks of treatment, and at the end of the study in heparinized tubes and immediately centrifuged. The plasma was stored at $-80^{\circ} \mathrm{C}$ until analysis for carotenoids such as lycopene, $\alpha$-, and $\beta$-carotene by high-performance liquid chromatography, as previously described $[6,17,18]$. In addition, the colorless carotenoids phytofluene and phytoene were measured because these precursors of carotenoids absorb radiation in the UV range $[19,20]$.

\section{Assessment of Gene Expression}

Biopsies were taken $24 \mathrm{~h}$ after chromametry using 1.25 MED at visits 4 and 8 (Fig. 1b), snap frozen in liquid nitrogen and stored at $-80^{\circ} \mathrm{C}$ until further analysis as, previously described [21-23]. For the evaluation of UV-induced gene expression, the $2^{(-\Delta \Delta c(t))}$ method is used [24]. Gene expression is indicated as x-fold induction versus an unirradiated control. Primer pairs were as follows:

ILla (forward 5' $5^{\prime}$-TGTATGGACTGCCCAAGATGAA-3', reverse 5'-ACTACCTGTGATGGTTTTGGGTATC-3', NM_ 000575.4) [25]; IL6 (forward 5' -CCTCGAGCCCACCGGGAACG-3', reverse 5' -AA-CTGGACCGAAGGCG-CTTGTG-3' ${ }^{\prime}$ NM_ 000600.4) [26]; IL10 (forward 5'-AAGACCCAGACATC-AAGGCG-3', reverse 5'-AATCGATGACAGCGCCGTAG-3', NM 000572.3) [27]; TNFa (forward 5'-GGAGAAGGGTG-ACCGACTCA-3', reverse 5' ${ }^{\prime}$ TGCCCAGACTCGGCAAAG-3', NM 000594.3) [28]; and 18S rRNA as housekeeping gene (forward 5'-GCCGCTAGAGGTGAAATTCTTG-3', reverse 5' -CATTCTTGGCAAATGCTTTCG-3', X03205.1) [29].

\section{Sample Size and Statistical Evaluation}

Sample size calculation was based on previously conducted studies by Lycored employing different carotenoid-rich formulations (Lyc-O-Mato and Lyc-O-Guard drink) for the primary endpoint "protection against ultraviolet (UV) light-induced erythema," such as $[19,30,31]$. The sample size corresponds to an effect size difference at 12 weeks between the two groups, with a power of $80 \%$ and a drop-out rate of $10 \%$.

Data management and randomization were done by Medistat Ltd. (Tel-Aviv, Israel). Additional studies were performed inhouse with the help of SigmaPlot (version 14.0). Normality of the data was tested using the Shapiro-Wilk test. For comparison of significant differences, the Kruskal-Wallis one-way ANOVA on ranks, $t$ test, or Mann-Whitney rank sum tests were performed.

\section{Results and Discussion}

For the active arm of the study, 75 volunteers were recruited, and 71 completed the study. For the placebo arm, all 74 recruited volunteers also finished the trial (Fig. 1a).

The treatment was safe and well tolerated, and no serious adverse events were observed within the two study populations. Only one severe adverse event diagnosed as pityriasis rosea occurred in the group with carotenoidrich TNC intake. In addition, one volunteer in the same group discontinued the study due to mild eczema. Compliance was good in both arms, which was reflected by the carotenoid levels determined at the end of the 5-week washout phase (visit 2), after 4 weeks of intake (visit 5), and at the end of the 12 weeks of intake (visit 8) (Fig. 1b, $2 \mathrm{a}-\mathrm{c}$ ) from blood samples. In detail, after 5 weeks of diet 


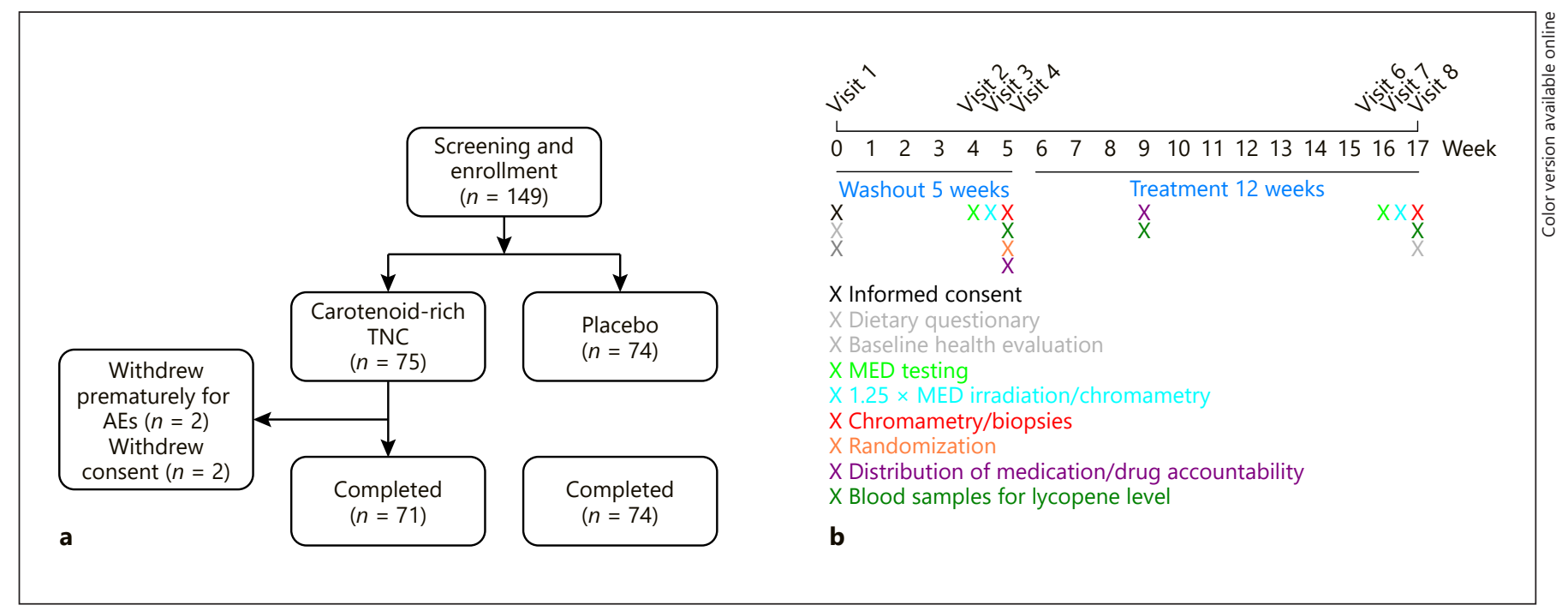

Fig. 1. Design of the study. a Overall trial design giving the number of volunteers per protocol and the corresponding dropouts. AEs, adverse events. b Details for both arms of the double-blind, randomized, placebo-controlled, multicenter study as performed in each of the centers. Shown are only those visits at which data were collected.

restriction, the starting median (25th percentile-75th percentile) lycopene level was $670 \mathrm{nM}(480-919)$ for the group to take the placebo, and $646 \mathrm{nM}(488-890)$ for the group to take the carotenoid-rich TNC. During the supplementation phase, the lycopene level significantly increased in the carotenoid-rich TNC-taking group to a median of $1,220 \mathrm{nM}(832-1,520)$ and reached a final median level of 1,153 nM (847-1,551), whereas no such increase was seen in the placebo group. There, median levels of $690 \mathrm{nM}(472-1,017)$ after 4 weeks and $720 \mathrm{nM}(445-$ $1,040)$ after 12 weeks were detected.

Similarly, the colorless carotenoid precursor phytofluene significantly increased in the carotenoid-rich TNC arm over time. Median phytofluene was $51 \mathrm{nM}(18-94)$ at the end of the washout phase and increased to $178 \mathrm{nM}$ (79-329) and to $156 \mathrm{nM}$ (66-390) during the supplementation phase in the active arm. In contrast, in the placebo part of the study, phytofluene was $55 \mathrm{nM}(18-108)$ in the depletion phase, which did not significantly change during the intake phase to $67 \mathrm{nM} \mathrm{(20-117)} \mathrm{and} 55 \mathrm{nM}(20-$ 108) (Fig. 2b).

Finally, the colorless carotenoid precursor phytoene also significantly increased during the intake phase of the active arm (Fig. 2c). Median phytoene was $50 \mathrm{nM}$ (18-90) at the end of the washout in the group supposed to take the active supplement and increased to $90 \mathrm{nM}(78-174)$ and to $90 \mathrm{nM}(66-154)$ over the supplementation phase.
In the placebo group, the initial median phytoene was 29 $\mathrm{nM}(16-90)$. In the supplementation phase, these data did not change and were $52 \mathrm{nM}(18-90)$ and $38 \mathrm{nM}(18-90)$.

Whether the determination of the nutritional supplements such as lycopene from blood samples is a good indicator for compliance and/or bioavailability should be reconsidered because a significant increase in the corresponding plasma levels not always correlates to a significant photoprotection [19]. In this regard, it may be interesting that cutaneous lycopene can also be determined noninvasively by Raman spectroscopy [32], where gender-related differences in basal carotene and lycopene levels have recently been observed.

The first primary outcome, the MED reading, was identical in both intended treatment groups, given as a median ( $\min , \max )$ of $0.080(0.035,0.125)$ after the washout phase. After supplementation with carotenoid-rich TNC, the MED did not change significantly; we observed a median (min, max) of 0.080 (0.035, 0.147; data not shown). This negative result is in line with observations obtained in a human intervention study over 12 weeks, where the MED was compared in a group of 9 females with skin type II receiving $55 \mathrm{~g}$ tomato corresponding to $16 \mathrm{mg}$ lycopene in tomato paste to a control group ( $n=$ 8) taking olive oil [33] and in a comparative 10-week study, where 10 females consumed either a pill or tomato paste corresponding to $16 \mathrm{mg}$ lycopene [34]. In this re- 


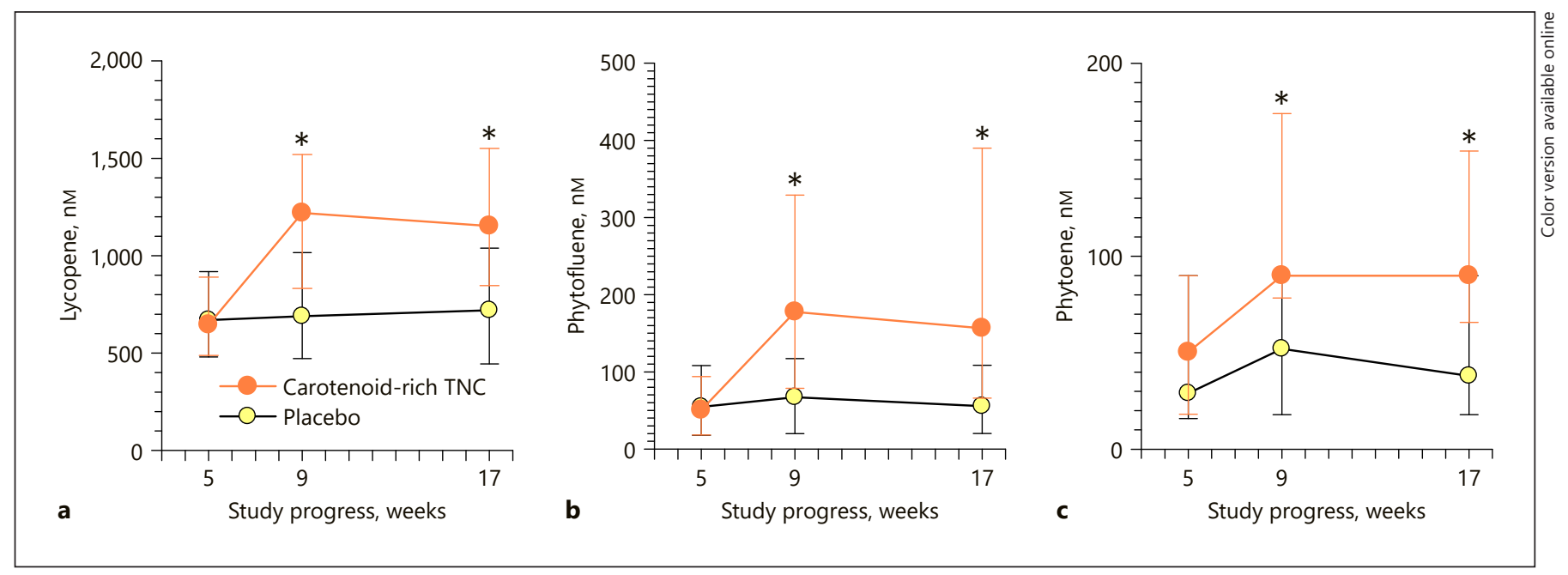

Fig. 2. Compliance reflected by carotenoid blood levels. Lycopene (a) phytofluene (b), and phytoene (c) content in blood samples taken at the indicated time points was determined as described in Materials and Methods. Given are medians, 75th and 25th percentiles from $n=71$ volunteers taking carotenoid-rich TNC and $n=$
74 volunteers taking placebo. Significance was determined by Kruskal-Wallis one-way ANOVA on ranks (Dunn's) for each time point compared to the starting level at week $5, * p<0.05$ versus week 5 (beginning of supplementation).
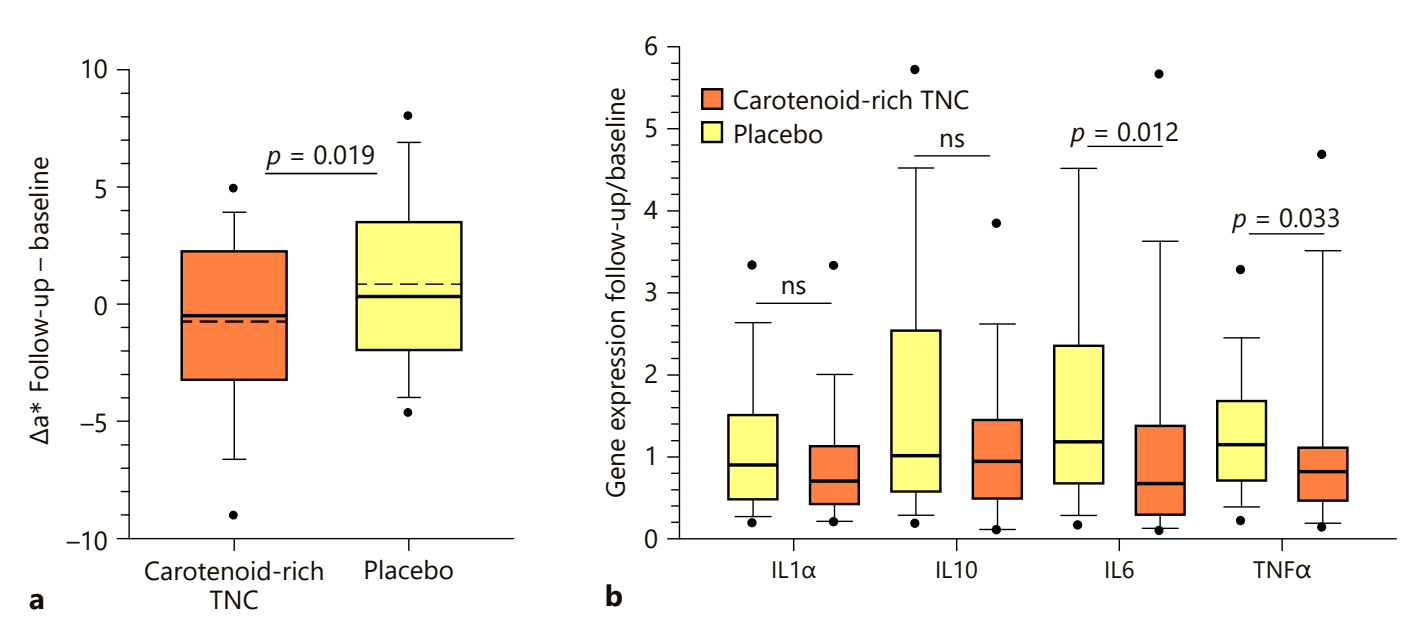

Fig. 3. Effect of carotenoid-rich TNC on erythema formation and gene expression. a Change of erythema $\left(\Delta \mathrm{a}^{*}\right)$ formation was determined by chromametry, as described in Materials and Methods, from $n=71$ volunteers taking carotenoid-rich TNC and $n=74$ volunteers taking placebo. $\Delta \mathrm{a}^{*}$ is defined as the difference between erythema development levels at $24 \mathrm{~h}$ following UV irradiation after supplementation (visit 8) and erythema development levels at $24 \mathrm{~h}$ following UV irradiation before supplementation (visit 4). Given are the differences by box plots with medians (solid line) and means (dashed line), dots represent outliers, and error bars represent the 95th and 5th percentiles. Significance between the treat- ment groups was determined by the $t$ test; $p<0.05$ and as indicated. $\mathbf{b}$ Gene expression analysis presented as quotient of gene induction after 12 weeks of supplementation with carotenoid-rich TNC or placebo (visit 8) divided by gene induction before supplementation (visit 4 ) from $n=46$ volunteers taking carotenoid-rich TNC and $n=48$ volunteers taking placebo. Given are the quotients as box plots with medians; dots represent outliers, and error bars represent the 95 th and 5 th percentiles. Significance between the treatment groups was determined by the Mann-Whitney rank sum test; $p<0.05$ and as indicated. ns, not significant. 
gard, we must keep in mind that the MED was determined by expert grading in all three studies. Interestingly, Rizwan et al. [33] nevertheless observed a significant increase in the erythema index $\mathrm{D}_{30}$ in the tomato paste-consuming group employing a reflectance instrument as compared to the start conditions.

The second primary outcome was the change of erythema $\Delta \mathrm{a}^{*}$ determined chromametrically (Fig. 3a). Here, we observed a significant difference between the two treatment groups ( $n=71$ for carotenoid-rich TNC, and $n=74$ for placebo). As expected, the change of erythema $\mathrm{a}^{*}$ after supplementation with carotenoid-rich TNC decreased less than after supplementation with placebo. This can be seen when we use the difference $\Delta \mathrm{a}^{*}$ of the follow-up minus $\Delta \mathrm{a}^{*}$ of the baseline. In case of the carotenoid-rich TNC, the response under treatment is lower, and we get a difference below zero. In case of the placebo, the erythema responses after supplementation are not lower, and therefore the difference (follow-up minus baseline) is not below zero. These results corroborate a previous study where a group of nine volunteers eating tomato paste corresponding to $16 \mathrm{mg}$ lycopene, $0.5 \mathrm{mg}$ $\beta$-carotene, and $0.1 \mathrm{mg}$ lutein over a 10 -week period presented with a significantly decreased $\Delta \mathrm{a}^{*} 24 \mathrm{~h}$ after 1.25 MED, while the placebo group of ten people having $10 \mathrm{~g}$ of olive oil did not [35]. Similarly, comparing the efficacy of a 12-week intake of either synthetic lycopene, a tomato extract (Lyc-o-Mato), or a drink containing solubilized Lyc-o-Mato (Lyc-o-Guard-Drink) in a parallel-group design $(n=36)$ indicated a significantly decreased $\Delta \mathrm{a}^{*} 24 \mathrm{~h}$ after a 1.25 MED irradiation in the groups taking approximately $10 \mathrm{mg} /$ day natural lycopene [19].

The difference to MED determination where we failed in finding protection by the active supplement may be explained by (i) a higher UV dose applied (1.25 MED instead of 1 MED) and by (ii) a higher sensitivity due to an objective detection device, as already shown by Rizwan et al. [33].

A change of skin color, e.g., skin tanning evaluated as $\Delta \mathrm{L}^{*}$ or $\triangle \mathrm{ITA}$, was not observed during the study, no matter whether analyzing the whole population or stratified according to seasonal enrollment. The effect of carotene intake on skin color is still under debate because contradicting results were observed from having an impact only on skin yellowness $b^{*}[36,37]$ and or redness $a^{*}$ [38].

The lycopene-rich TNC assessed in the current study contained $15 \mathrm{mg}$ lycopene, $5.8 \mathrm{mg}$ phytoene and phytofluene, $0.8 \mathrm{mg} \beta$-carotene, $5.6 \mathrm{mg}$ tocopherols from tomato extract, and $4 \mathrm{mg}$ carnosic acid from rosemary extract per day because previous in vitro studies/animal studies indicated a synergistic inhibition of LPS-induced $\mathrm{NO}$ production, $\mathrm{TNF} \alpha-$, superoxide and $\mathrm{PGE}_{2}$ release in macrophages and in a mouse model of peritonitis by lycopene, $\beta$-carotene, and the phenolic carnosic acid [39]. Similarly, synergistic inhibition of oxidative stress in a mouse tumor model [40] or inhibition of androgen signaling and PSA secretion by lycopene and tocopherol [41] was determined. In addition, the synergistic effect of a TNC and carnosic acid (from rosemary) has recently been observed on inhibition of UVB-induced IL6 secretion in keratinocytes as compared to the single interventions (Calniquer et al., unpublished data).

As secondary outcome, we determined UV-induced gene upregulation of markers associated with immunosuppression or inflammation in biopsies taken at visits 4 and 8 . For ethical reasons, we did not take biopsies from all volunteers. Similarly, as for the erythema data $\Delta \mathrm{a}^{*}$ (Fig. 2b), we further processed the relative gene expression data by building a quotient of induction after supplementation divided by induction before supplementation (Fig. 2c). For the markers IL-1 $\alpha$ and IL10, we did not see a significant improvement by supplementation with carotenoid-rich TNC. In contrast, we saw a significant decrease in the UV response after carotenoid-rich TNC intake as compared to the placebo treatment. Assessment of molecular markers might foster the sensitivity of such studies as shown by a significantly decreased expression of UV-induced matrix metalloproteinase 1 postsupplementation in the lycopene-taking group as compared to the olive oil-taking group [33] or in our previous study [6].

Finally, it should be noted that the daily amount of lycopene used in the current study corresponds to $52 \mathrm{~g}$ canned tomato paste and that of $\beta$-carotene to $90 \mathrm{~g}$ [42]. The amount of vitamin $\mathrm{E}$ would be obtained by a daily intake of $130 \mathrm{~g}$ of canned tomato paste [42].

\section{Conclusion}

Carotenoid-rich TNC is a safe and well-tolerated nutritional supplement suited for significant protection from (i) UVB-induced erythema formation and (ii) UVBinduced upregulation of IL6 and TNFa.

\section{Acknowledgement}

The technical support of Heidi Brenden and Ingo Felsner in the analysis of the skin biopsies and the help of the study nurses Lydie Weiand and June Gardner is highly appreciated. 


\section{Statement of Ethics}

Subjects have given their written informed consent. This multicenter study was approved by the local committees of all participating centers. The study was conducted according to the Declaration of Helsinki principles (2013).

\section{Disclosure Statement}

Krutmann, Moseley, and Ferguson obtained funding. The other authors have no conflicts of interest to disclose.

\section{Funding Sources}

The costs of conducting this study were paid by Lycored Ltd. Be'er Sheva, Israel.

\section{Author Contributions}

Drs. Marini, Grether-Beck, Jaenicke, and Krutmann had full access to all data in the study and take the responsibility for the integrity of the data and the accuracy of the data analysis.

All authors contributed to the study concept and design.

Groten, Marini, Ibbotson, Grether-Beck, Jaenicke, Moseley, Ferguson, and Krutmann were responsible for the acquisition, analysis, and interpretation of the data.

Krutmann, Grether-Beck, Marini, and Groten drafted the manuscript.

Ferguson, Moseley, Ibbotson, and Jaenicke made a critical revision of the manuscript for important intellectual content.

Groten, Grether-Beck, Jaenicke, and Marini made the statistical analysis.

All authors provided administrative, technical, or material support.

Krutmann had the supervision of the study.

\section{References}

1 Krutmann J, Humbert P, editors. Nutrition for Healthy Skin: Strategies for Clinical and Cosmetic Practice. Berlin, Heidelberg: Springer; 2011.

2 Stahl W. Systemic photoprotection by carotinoids. In: Krutmann JH, P, editors. Nutrition for Healthy Skin: Strategies for Clinical and Cosmetic Practice. Berlin, Heidelberg: Springer; 2011. p. 65-70.

3 Gonzalez S, Gilaberte Y, Philips N, Juarranz A. Current trends in photoprotection - a new generation of oral photoprotectors. Open Dermatol J. 2011;5(1):6-14.

4 Köpcke W, Krutmann J. Protection from sunburn with beta-Carotene-a meta-analysis. Photochem Photobiol. 2008 Mar-Apr;84(2): 284-8.

5 Krinsky NI, Johnson EJ. Carotenoid actions and their relation to health and disease. Mol Aspects Med. 2005 Dec;26(6):459-516.

6 Grether-Beck S, Marini A, Jaenicke T, Stahl W, Krutmann J. Molecular evidence that oral supplementation with lycopene or lutein protects human skin against ultraviolet radiation: results from a double-blinded, placebo-controlled, crossover study. Br J Dermatol. 2017 May;176(5):1231-40.

7 Kondo S, Sauder DN, Kono T, Galley KA, McKenzie RC. Differential modulation of interleukin-1 alpha (IL-1 alpha) and interleukin-1 beta (IL-1 beta) in human epidermal keratinocytes by UVB. Exp Dermatol. 1994 Feb;3(1):29-39.

8 Ansel JC, Luger TA, Green I. The effect of in vitro and in vivo UV irradiation on the production of ETAF activity by human and murine keratinocytes. J Invest Dermatol. 1983 Dec;81(6):519-23.
9 Enk AH, Saloga J, Becker D, Mohamadzadeh $\mathrm{M}$, Knop J. Induction of hapten-specific tolerance by interleukin 10 in vivo. J Exp Med. 1994 Apr;179(4):1397-402.

10 Köck A, Schwarz T, Kirnbauer R, Urbanski A, Perry P, Ansel JC, et al. Human keratinocytes are a source for tumor necrosis factor alpha: evidence for synthesis and release upon stimulation with endotoxin or ultraviolet light. J Exp Med. 1990 Dec;172(6):1609-14.

11 Urbanski A, Schwarz T, Neuner P, Krutmann J, Kirnbauer R, Köck A, et al. Ultraviolet light induces increased circulating interleukin-6 in humans. J Invest Dermatol. 1990 Jun;94(6): 808-11.

12 Takashima A, Bergstresser PR. Impact of UVB radiation on the epidermal cytokine network. Photochem Photobiol. 1996 Apr;63(4): 397-400.

13 Bashir MM, Sharma MR, Werth VP. UVB and proinflammatory cytokines synergistically activate TNF-alpha production in keratinocytes through enhanced gene transcription. J Invest Dermatol. 2009 Apr;129(4):9941001.

14 Clarys P, Alewaeters K, Lambrecht R, Barel AO. Skin color measurements: comparison between three instruments: the Chromameter(R), theDermaSpectrometer(R) and the Mexameter(R). Skin Res Technol. 2000 Nov;6(4):230-8.

15 Piérard GE. EEMCO guidance for the assessment of skin colour. J Eur Acad Dermatol Venereol. 1998 Jan;10(1):1-11.

16 Heinrich U, Neukam K, Tronnier H, Sies H, Stahl W. Long-term ingestion of high flavanol cocoa provides photoprotection against UVinduced erythema and improves skin condition in women. J Nutr. 2006 Jun;136(6):15659.
17 Polidori MC, Carrillo JC, Verde PE, Sies H, Siegrist J, Stahl W. Plasma micronutrient status is improved after a 3-month dietary intervention with 5 daily portions of fruits and vegetables: implications for optimal antioxidant levels. Nutr J. 2009 Feb;8(1):10.

18 Stahl W, Sundquist AR, Hanusch M, Schwarz W, Sies H. Separation of beta-carotene and lycopene geometrical isomers in biological samples. Clin Chem. 1993 May;39(5):810-4.

19 Aust O, Stahl W, Sies H, Tronnier H, Heinrich U. Supplementation with tomato-based products increases lycopene, phytofluene, and phytoene levels in human serum and protects against UV-light-induced erythema. Int J Vitam Nutr Res. 2005 Jan;75(1):54-60.

20 Fuller B, Smith D, Howerton A, Kern D. Antiinflammatory effects of CoQ10 and colorless carotenoids. J Cosmet Dermatol. 2006 Mar; 5(1):30-8.

21 Grether-Beck S, Marini A, Jaenicke T, Krutmann J. Effective photoprotection of human skin against infrared A radiation by topically applied antioxidants: results from a vehicle controlled, double-blind, randomized study. Photochem Photobiol. 2015 Jan-Feb;91(1): 248-50.

22 Grether-Beck S, Marini A, Jaenicke T, Krutmann J. French Maritime Pine Bark Extract $\left(\right.$ Pycnogenol $^{\circledR}$ ) Effects on Human Skin: Clinical and Molecular Evidence. Skin Pharmacol Physiol. 2016;29(1):13-7.

23 Marini A, Grether-Beck S, Jaenicke T, Weber M, Burki C, Formann P, et al. Pycnogenol ${ }^{\circledR}$ effects on skin elasticity and hydration coincide with increased gene expressions of collagen type I and hyaluronic acid synthase in women. Skin Pharmacol Physiol. 2012;25(2): 86-92. 
24 Livak KJ, Schmittgen TD. Analysis of relative gene expression data using real-time quantitative PCR and the 2(-Delta Delta C(T)) Method. Methods. 2001 Dec;25(4):402-8.

25 Nishida T, Nishino N, Takano M, Kawai K, Bando K, Masui Y, et al. cDNA cloning of IL-1 alpha and IL-1 beta from mRNA of U937 cell line. Biochem Biophys Res Commun. 1987 Feb;143(1):345-52.

26 May LT, Helfgott DC, Sehgal PB. Anti-betainterferon antibodies inhibit the increased expression of HLA-B7 mRNA in tumor necrosis factor-treated human fibroblasts: structural studies of the beta 2 interferon involved. Proc Natl Acad Sci USA. 1986 Dec;83(23):895761.

27 Vieira P, de Waal-Malefyt R, Dang MN, Johnson KE, Kastelein R, Fiorentino DF, et al. Isolation and expression of human cytokine synthesis inhibitory factor cDNA clones: homology to Epstein-Barr virus open reading frame BCRFI. Proc Natl Acad Sci USA. 1991 Feb; 88(4):1172-6.

28 Pennica D, Nedwin GE, Hayflick JS, Seeburg PH, Derynck R, Palladino MA, et al. Human tumour necrosis factor: precursor structure, expression and homology to lymphotoxin. Nature. 1984 Dec;312(5996):724-9.

29 McCallum FS, Maden BE. Human $18 \mathrm{~S}$ ribosomal RNA sequence inferred from DNA sequence. Variations in $18 \mathrm{~S}$ sequences and secondary modification patterns between vertebrates. Biochem J. 1985 Dec;232(3):725-33.
30 Stahl W, Heinrich U, Aust O, Tronnier H, Sies $\mathrm{H}$. Lycopene-rich products and dietary photoprotection. Photochem Photobiol Sci. 2006 Feb;5(2):238-42.

31 Stahl W, Sies H. Bioactivity and protective effects of natural carotenoids. Biochim Biophys Acta. 2005 May;1740(2):101-7.

32 Megow I, Darvin ME, Meinke MC, Lademann J. A Randomized Controlled Trial of Green Tea Beverages on the in vivo Radical Scavenging Activity in Human Skin. Skin Pharmacol Physiol. 2017;30(5):225-33.

33 Rizwan M, Rodriguez-Blanco I, Harbottle A, Birch-Machin MA, Watson RE, Rhodes LE. Tomato paste rich in lycopene protects against cutaneous photodamage in humans in vivo: a randomized controlled trial. Br J Dermatol. 2011 Jan;164(1):154-62.

34 Sokoloski L, Borges M, Bagatin E. Lycopene not in pill, nor in natura has photoprotective systemic effect. Arch Dermatol Res. 2015 Aug;307(6):545-9.

35 Stahl W, Heinrich U, Wiseman S, Eichler O, Sies H, Tronnier H. Dietary tomato paste protects against ultraviolet light-induced erythema in humans. J Nutr. 2001 May;131(5): 1449-51.

36 Alaluf S, Heinrich U, Stahl W, Tronnier H, Wiseman S. Dietary carotenoids contribute to normal human skin color and UV photosensitivity. J Nutr. 2002 Mar;132(3):399-403.

37 Pezdirc K, Hutchesson MJ, Williams RL, Rollo ME, Burrows TL, Wood LG, et al. Consuming High-Carotenoid Fruit and Vegetables Influences Skin Yellowness and Plasma Carotenoids in Young Women: A Single-Blind Randomized Crossover Trial. J Acad Nutr Diet. 2016 Aug;116(8):1257-65.
38 Whitehead RD, Re D, Xiao D, Ozakinci G, Perrett DI. You are what you eat: within-subject increases in fruit and vegetable consumption confer beneficial skin-color changes. PLoS One. 2012;7(3):e32988.

39 Hadad N, Levy R. The synergistic anti-inflammatory effects of lycopene, lutein, $\beta$-carotene, and carnosic acid combinations via redoxbased inhibition of NF-kB signaling. Free Radic Biol Med. 2012 Oct;53(7):1381-91.

40 Al-Malki AL, Moselhy SS, Refai MY. Synergistic effect of lycopene and tocopherol against oxidative stress and mammary tumorigenesis induced by 7,12-dimethyl[a]benzanthracene in female rats. Toxicol Ind Health. 2012 Jul;28(6):542-8.

41 Linnewiel-Hermoni K, Khanin M, Danilenko M, Zango G, Amosi Y, Levy J, et al. The anticancer effects of carotenoids and other phytonutrients resides in their combined activity. Arch Biochem Biophys. 2015 Apr;572:28-35.

42 US Department of Agriculture, Agricultural Research Service, Nutrient Data Laboratory [Internet]. USDA National Nutrient Database for Standard Reference, Legacy. Published April 2018 [last access 2018 Dec]. Available from: https://www.ars.usda.gov/ northeast-area/beltsville-md-bhnrc/beltsville-human-nutrition-research-center/nutrient-data-laboratory/docs/usda-nationalnutrient-database-for-standard-reference/. 